\title{
PERTUMBUHAN KEPITING BAKAU, BANDENG DAN NILA MERAH DI TAMBAK TANAH GAMBUT'
}

\author{
Adi Hanafi ${ }^{*}$, Akhmad Mustafa ${ }^{*}$ dan Brata Pantjara ${ }^{*}$ )
}

\begin{abstract}
ABSTRAK
Produktivitas tambak tanah gambut yang baru dibangun untuk budidaya udang windu rendah yang disebabkan oleh kualitas lingkungan yang kurang baik. Kepiting bakau, bandeng dan nila merah diperkirakan lebih sesuai untuk kondisi yang demikian. Penelitian budidaya kepiting bakau, bandeng dan nila merah sebagai perlakuan dilakukan untuk mengetahui pertumbuhannya pada tambak tanah gambut. Padat penebaran yang diaplikasikan untuk kepiting bakau, bandeng dan nila merah berturut-turut 200; 600 dan 800 ekor/petak dengan masing-masing tiga ulangan. Berat awal kepiting bakau, bandeng dan nila merah berturut-turut 27,63;0,42 dan 1,38 g. Petakan yang digunakan berukuran $400 \mathrm{~m}^{2}$ dengan penggantian air sekitar $10 \%$ volume total/hari secara gravitasi. Hasil penelitian menunjukkan bahwa kepiting bakau, bandeng dan nila merah dapat mencapai berat berturut-turut 166,33; 145,35 dan 126,67 $\mathrm{g}$ sesudah dipelihara selama 14 minggu di tambak tanah gambut.
\end{abstract}

ABSTRACT: Growth of Mud Crab, Milkfish and Red Nifi in Brackishwater Peat Soil Pond, by: Adi Hanafi, Akbmad Mustafa and Brate Pantjara

The productivity of newly constructed peat soil pond for tiger prawn culture is very low due to poor environmental quality. Mud crab, milkfish and red nifi are expected to be adaptable in this condition. Research on the culture of these commodities were done to investigate the growth rate under peat soil pond. The stocking density of the mud crab, milkfish and red nifi were 200; 600 and 800 ind./pond of $400 \mathrm{~m}^{2}$, respectively and replicate three times each. Water exchange is $10 \%$ of total volume/day. The initial weight were $27.63 \mathrm{~g}$ for mud crab, $0.42 \mathrm{~g}$ for milkfish and 1.38 for red nifi. The results showed that average weight after 14 weeks culture for mud crab, milkfish and red nifi were $166.33,145.35$ and $126.67 \mathrm{~g}$ respectively.

KEYWORDS: Mud crab, chanos, red tilapia

\section{PENDAHULUAN}

Peningkatan produksi perikanan budidaya di tambak selain dapat dilakukan melalui intensifikasi, juga dilakukan melalui ekstensifikasi dan diversifikasi. Peningkatan produksi budidaya tambak melalui ekstensifikasi, menuntut tersedianya lahan. Satu di antara jenis tanah yang cukup luas (sekitar 10,9 juta ha) di Indonesia dan potensial untuk dijadikan tambak adalah tanah gambut.

Berbagai masalah tanah gambut dalam pemanfaatannya untuk pertanian meliputi kekurangan unsur hara, $\mathrm{pH}$ rendah, jenuh air, permukaan tanah yang turun saat kering, proses dekomposisi gambut yang lambat dan berbagai masalah lainnya (Davies et al., 1975). Di bidang budidaya perikanan, telah dilaporkan oleh Mustafa et al. (1992) bahwa udang windu (Penaeus monodon) hanya mencapai berat 19,01 g dengan kelangsungan hidup $31,25 \%$ yang 
dipelihara selama 4 bulan di tambak tanah gambut bukaan baru pada padat penebaran $4 \mathrm{ekor} / \mathrm{m}^{2}$, sedangkan di tambak non-gambut berat udang dapat mencapai $30-35 \mathrm{~g}$ dengan kelangsungan hidup minimal $50 \%$ pada kondisi dan lama pemeliharaan yang sama. Juga telah dilaporkan oleh Poernomo (1988) bahwa produktivitas tambak tanah gambut sangat rendah pada awalnya.

Untuk mengefektifkan penggunaan tambak tanah gambut bukaan baru, maka perlu dicari alternatif komoditas yang dapat tumbuh dan hidup secara optimal, sekaligus sebagai usaha diversifikasi untuk meningkatkan produksi budidaya di tambak. Pemilihan jenis komoditas merupakan satu di antara faktor yang menentukan keberhasilan produksi di tanah gambut selain pengelolaan air, pemupukan, dan pengapuran (AARD dan LAWOO 1990 dalam Klepper, 1990) Kepiting bakau (Scylla serrata), bandeng (Chanos chanos), dan nila merah (Oreochromis niloticus) dikenal sebagai organisme air yang relatif tahan terhadap berbagai kondisi di tambak.

Percobaan ini bertujuan untuk mengetahui pertumbuhan kepiting bakau, bandeng dan nila merah dalam rangka diversifikasi komoditas perikanan budidaya di tambak tanah gambut.

\section{BAHAN DAN METODE}

Percobaan dilakukan pada tambak tanah gambut di Delta Tampina, Kecamatan Malili, Kabupaten Luwu, Sulawesi Selatan. Tambak yang digunakan berukuran $400 \mathrm{~m}^{2}$ sebanyak 9 petak. Khusus untuk tambak budidaya kepiting bakau, dipasang pagar bambu pada bagian dalam pematang setinggi 1,25 m di atas pelataran tambak dan $50 \mathrm{~cm}$ tertanam pada dasar tambak. Setiap petak tambak dilengkapi dengan 1 pintu air lebar $60 \mathrm{~cm}$ dan 1 pipa goyang berdiameter 8 inci. Dalam persiapan tambak dilakukan pemberantasan hama dengan menggunakan saponin dosis $30 \mathrm{ppm}$, pengapuran dengan kapur pertanian dosis $2 \mathrm{t} / \mathrm{ha}$, pemberian pupuk urea dan TSP masing-masing 200 dan $100 \mathrm{~kg} / \mathrm{ha}$.

Perlakuan yang dicobakan adalah berbagai komoditas budidaya perikanan yaitu: kepiting bakau, bandeng, dan nila merah, masing-masing dengan tiga ulangan.

Padat penebaran yang diaplikasikan untuk kepiting bakau, bandeng, dan nila merah berturut-turut adalah 200, 600, dan 800 ekor/petak. Berat awal kepiting bakau, bandeng dan nila merah berturut-turut 27,$63 ; 0,42$ dan $1,38 \mathrm{~g}$. Rasio jenis kelamin jantan:betina yang diaplikasikan untuk kepiting bakau adalah 1:1. Pakan yang diberikan untuk kepiting bakau berupa ikan rucah kering sedangkan untuk bandeng dan nila merah berupa pelet (kandungan protein sekitar $18 \%$ ) masing-masing $5 \%$ dari berat total yang diberikan dua kali sehari (pagi dan sore hari). Pergantian air dilakukan setiap hari sekitar 10\% dari volume total secara gravitasi. Pengapuran sebanyak $1 \mathrm{~kg} / 10 \mathrm{~m}$ panjang pematang yang ditebar merata di kaki pematang dilakukan setiap menjelang 
turun hujan (Mustafa et al., 1992). Pemupukan susulan sebanyak 10\% dari dosis awal pupuk anorganik dilakukan setiap 2 minggu.

Pengukuran berat hewan uji dilakukan setiap dua minggu dengan menggunakan timbangan dengan ketelitian 0,1 g. Pengukuran kualitas air yang langsung di lapangan berupa $\mathrm{pH}$ (dengan $\mathrm{pH}$ solution), salinitas (dengan refraktometer), suhu (dengan termometer), kecerahan (piring sechi), dan kedalaman (dengan tongkat penduga) dilakukan setiap hari. Peubah kualitas air dianalisis di Laboratorium Kimia Balitkanta Maros setiap dua minggu berupa $\mathrm{NO}_{2}-\mathrm{N}, \mathrm{NO}_{3}-\mathrm{N}, \mathrm{NH}_{4}-\mathrm{N}, \mathrm{PO}_{4}-\mathrm{P}$, bahan organik total, $\mathrm{Fe}, \mathrm{Al}$, dan $\mathrm{SO}_{4}$. Di samping itu juga dilakukan pengukuran oksigen terlarut dan suhu air setiap 4 jam selama periode 24 jam yang dilakukan setiap empat minggu sekali. Pengambilan contoh tanah dilakukan sebelum persiapan tambak. Pengamatan terakhir berupa pengukuran berat dilakukan pada saat pemeliharaan berlangsung sampai 14 minggu. Data yang diperoleh dianalisis secara deskriptif.

\section{HASIL DAN PEMBAHASAN}

\section{Kualitas Tanah}

Kualitas tanah tambak tanah gambut yang digunakan dalam penelitian terlihat pada Tabel 1, di mana $\mathrm{pH}$, redoks, kandungan bahan organik, $\mathrm{N}, \mathrm{Fe}$, dan Al serta rasio C-N relatif sama. Angka keasaman $(\mathrm{pH})$ tanah masih tergolong masam, kandungan bahan organik, $\mathrm{Fe}$, dan Al sangat tinggi, serta rasio $\mathrm{C}-\mathrm{N}$ sangat tinggi pula. Kualitas tanah tersebut secara umum belum mendukung usaha budidaya di tambak. Seperti dikatakan oleh Potter (1976) bahwa pH tambak yang baik adalah 6,5-8,0, kandungan bahan organik yang layak bagi pertumbuhan makanan alami di tambak adalah $9 \%$ (Villaluz dalam ASEAN 1976) dan rasio C-N tanah yang baik untuk tambak adalah 16.

Khusus untuk kepiting bakau, kondisi tanah demikian diduga bukan merupakan masalah sebab hutan bakau memang merupakan habitatnya. Penggemukan kepiting bakau telah berhasil dilakukan dalam hutan bakau yang tidak ditebang pohonnya di Vietnam (Le Than Hung, 1992), walaupun ada perbedaan jika dibandingkan dengan kualitas tanah pada tambak tanah gambut akibat dari penggalian. Demikian juga halnya dengan ikan nila merah, seperti yang dilaporkan oleh Arifin dan Nasution (1992) bahwa ikan nila merah dapat tumbuh dengan baik pada tanah sulfat masam di lahan rawa pasang surut.

\section{Kualitas Air}

Kualitas air yang diukur langsung di lapangan relatif sama di antara perlakuan, dalam hal ini jenis komoditas yang dibudidayakan tidak dipengaruhi dan mempengaruhi kualitas air (Tabel 2).

Angka keasaman $(\mathrm{pH})$ air selama percobaan berkisar 6,5-8,0 atau termasuk netral. Pada umumnya komoditas perikanan menghendaki $\mathrm{pH}$ air yang netral. 
Menurut Gunarto et al. (1987) $\mathrm{pH}$ air yang baik untuk pertumbuhan kepiting bakau adalah 6,5-8,5. Selanjutnya Wheaton (1977) menyatakan bahwa $\mathrm{pH}$ air yang baik bagi kehidupan ikan adalah 6,4-8,5.

Tabel 1. Kualitas tanah tambak tanah gambut untuk budidaya kepiting bakau, bandeng dan nila merah

Table 1. Soil quality of brackisbwater peat soil pond for mud crab, milkfish and red nifi culture

\begin{tabular}{|c|c|c|c|c|c|c|c|}
\hline \multirow[t]{2}{*}{$\begin{array}{l}\text { Komoditts } \\
\text { Commodity }\end{array}$} & \multicolumn{2}{|c|}{$\begin{array}{l}\text { pH/Redoks (V) } \\
\text { pH/Redox (V) }\end{array}$} & \multirow{2}{*}{$\begin{array}{l}\text { Bahon organik } \\
\text { Organic master } \\
(\%)\end{array}$} & \multirow{2}{*}{ (\%) } & \multirow{2}{*}{$\begin{array}{l}\text { CN } \\
\text { Rasio } \\
\text { Ratio }\end{array}$} & \multirow{2}{*}{$\begin{array}{c}\mathrm{Fe} \\
(\mathbf{p p m})\end{array}$} & \multirow{2}{*}{$\begin{array}{c}\mathbf{A} \text {. } \\
\text { (ppm) }\end{array}$} \\
\hline & $\mathrm{H}_{2} \mathrm{O}$ & $\mathbf{r C l}$ & & & & & \\
\hline $\begin{array}{l}\text { Kepiting bakau } \\
\text { (Mud crab) }\end{array}$ & $6,09 / 0,20$ & $6,30 / 0,17$ & 26,37 & 0,16 & 95 & 167,89 & 23,82 \\
\hline $\begin{array}{l}\text { Bandeng } \\
\text { (Milkfish) }\end{array}$ & $6,13 / 0,17$ & $6,22 / 0,16$ & 23,32 & 0,14 & 96 & 153,49 & 34,77 \\
\hline $\begin{array}{l}\text { Nila merah } \\
\text { (Red nifi) }\end{array}$ & $6,12 / 0,17$ & $6,24 / 0,16$ & 29,13 & 0,17 & 99 & 177,89 & 42,12 \\
\hline
\end{tabular}

Tabel 2. Kualitas air yang diukur di lapangan selama penelitian Table 2. In situ water quality during experiment

\begin{tabular}{|c|c|c|c|c|}
\hline \multirow{2}{*}{$\begin{array}{l}\text { Variabel } \\
\text { Variables }\end{array}$} & & \multicolumn{3}{|c|}{ Komoditas / Commodity } \\
\hline & & $\begin{array}{l}\text { Kepiting bakau } \\
\text { Mud crab }\end{array}$ & $\begin{array}{l}\text { Bandeng } \\
\text { Millkfis } b\end{array}$ & $\begin{array}{l}\text { Nila merah } \\
\text { Red tilapia }\end{array}$ \\
\hline \multicolumn{5}{|l|}{$\mathrm{pH}$} \\
\hline pagi & & $6,5-8,0(7,2)$ & $6,5-8,0(7,3)$ & $6,5-8,0(7,3)$ \\
\hline sore & & $6,5-8,5(7,6)$ & $6,5-8,5(7,6)$ & $6,5-8,5(7,7)$ \\
\hline Salinitas (salinity) & ppt & $9-17(13)$ & $9-16(13)$ & $9-16(13)$ \\
\hline Suhu (temperature) & oC & & & \\
\hline pagi & & $29-34(31)$ & $29-34(31)$ & $29-34(31)$ \\
\hline sore & & $30-36(33)$ & $30-36(33)$ & $30-36(33)$ \\
\hline Kecerahan (transparancy) & $\mathrm{cm}$ & $20-40(27)$ & $20-45(31)$ & $20-45(32)$ \\
\hline Kedalaman (depth) & $\mathrm{cm}$ & $50-65(60)$ & $50-70(63)$ & $50-70(63)$ \\
\hline
\end{tabular}

() : angka rata-rata (average value) 
Dari Tabel 2 terlihat bahwa rata-rata salinitas air tambak untuk semua perlakuan adalah 13 ppt dan termasuk dalam batas yang layak untuk ketiga jenis komoditas. Menurut Gunarto et al. (1987) kepiting bakau mampu hidup pada salinitas 0-32 ppt. Selanjutnya Wahyuni dan Ismail (1987) mengemukaan kepiting bakau dijumpai pada tambak dengan salinitas $14-34$ ppt, sedangkan Hill (1982) menyebutkan bahwa kepiting bakau mampu mentolerir salinitas sampai 60 ppt. Ikan bandeng juga mampu mentolerir rentang salinitas yang tinggi (Bardach et al., 1972). Sedangkan nila merah merupakan ikan air tawar yang bersifat eurihaline sehingga mampu beradaptasi pada perairan laut (Cholik et al., 1990).

Oksigen terlarut dan suhu air cukup berfluktuasi mengikuti waktu dan relatif sama pada ketiga perlakuan untuk waktu pengamatan yang sama (Gambar 1 dan 2). Oksigen terlarut yang kritis bagi ketiga jenis komoditas itu terjadi pada pukul 01.00 dan 05.00 WIT. Menurut Wheaton (1977) oksigen terlarut yang baik bagi kehidupan ikan minimal $3 \mathrm{ppm}$.

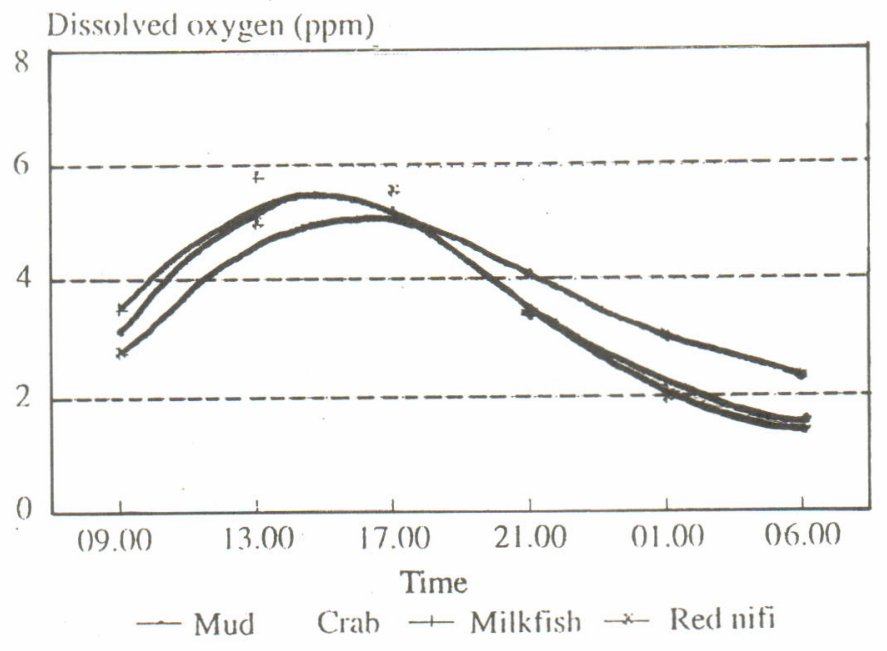

Gambar 1. Fluktuasi oksigen terlarut dalam tambak tanah gambut yang digunakan untuk budidaya kepiting bakau, bandeng dan nila merah

Figure 1. Fluctuation of dissolved oxygen in brackishwater peat soil pond used for mud crab, milkfish and red nifi culture 


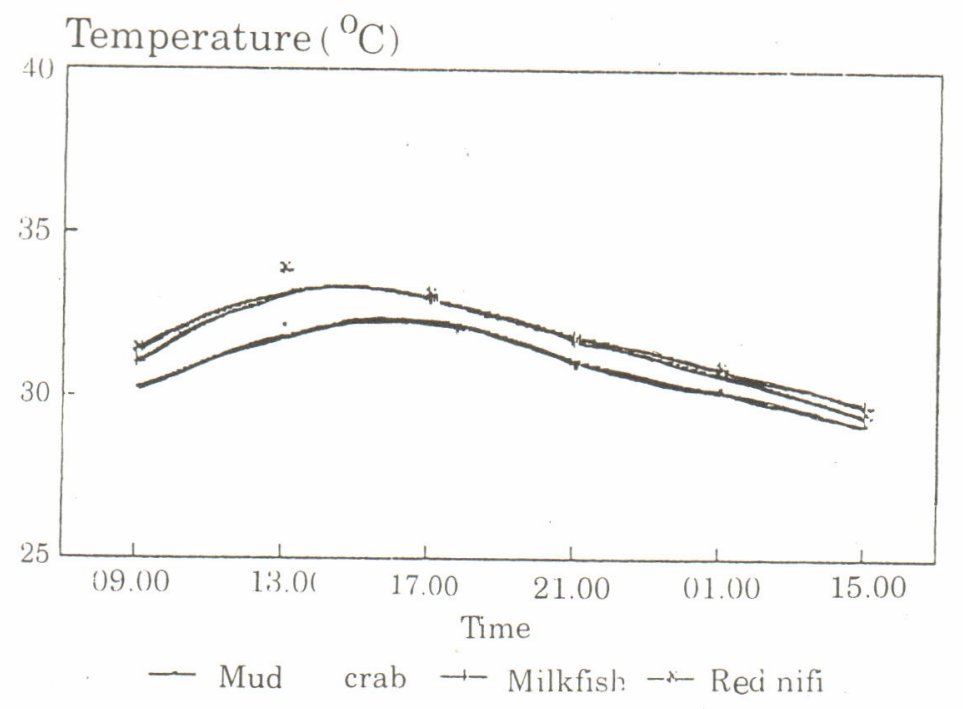

Gambar 2. Fluktuasi suhu air dalam tambak tanah gambut yang digunakan untuk budidaya kepiting bakau, bandeng dan nila merah

Figure 2. Fluctuation of water temperature in braçkishwater peat soil pond used for mud crab, milkfish and red nifi culture

Kandungan oksigen terlarut pada siang hari (pukul 09.00-17.00 WIT) berkisar 2,73-5,89 ppm, sedangkan pada malam hari (pukul 21.00-05.00 WIT) berkisar 1,40-2,93 ppm. Hal ini memberikan indikasi tidak adanya "blooming" fitoplankton yang biasa dicirikan oleh oksigen terlarut pada siang hari yang mencapai kejenuhan. Diduga bahwa oksigen terlarut banyak dipergunakan oleh mikroorganisme di samping degradasi bahan organik dan koloid yang membutuhkan oksigen terlarut.

Dari Gambar 2 terlihat bahwa suhu air dapat mencapai $36^{\circ} \mathrm{C}$ dengan rata-rata $33^{\circ} \mathrm{C}$ dan relatif sama pada semua perlakuan. Suhu air ini tergolong tinggi yang dapat disebabkan oleh warna air yang lebih banyak berwarna coklat sebagai akibat koloid organik yang dapat menyerap panas lebih banyak. Keberadaan partikel koloid dalam air tambak didukung pula oleh nilai kecerahan yang rendah (rata-rata berkisar $27-32 \mathrm{~cm}$ ). Baliao (1983) menyatakan bahwa kepiting bakau tumbuh lebih cepat pada suhu $23-32^{\circ} \mathrm{C}$. Mintardjo et al. (1984) menyatakan kisaran suhu yang optimal bagi kehidupan ikan di tambak adalah $25-32^{\circ} \mathrm{C}$. Selanjutnya Prasetyo (1988) menyatakan bahwa ikan nila merah sangat toleran terhadap perubahan lingkungan antara lain oksigen terlarut, salinitas, dan suhu air. 
Hasil analisis kualitas air dapat dilihat pada Lampiran 1. Terlihat bahwa kualitas air tersebut relatif sama di antara semua perlakuan yakni berbeda pada waktu pengukuran yang berbeda. Hal ini menunjukkan bahwa perlakuan yang dicobakan tidak memberikan pengaruh terhadap kualitas air, tetapi kualitas air itu berubah menurut waktu.

\section{Pertumbuhan}

Pertumbuhan berat dari ketiga jenis komoditas selama 14 minggu terlihat pada Gambar 3. Terlihat bahwa ketiga jenis komoditas masih menunjukkan peningkatan berat terutama kepiting bakau dan ikan bandeng. Untuk ikan nila merah setelah minggu ke-12 pertumbuhan beratnya relatif kecil, hal ini disebabkan nila merah telah mulai bereproduksi pada minggu ke-11. Nila merah relatif singkat dalam pematangan gonad yang selanjutnya terjadi pemijahan yang akan menambah besarnya populasi. Populasi yang besar akan mempengaruhi pertumbuhan berat individu (Prasetyo, 1983). Liao dan Chang (1983) menyatakan ikan nila merah mempunyai berat $100,69 \mathrm{~g}$ (jantan) dan $65,00 \mathrm{~g}$ (betina) di perairan tawar, $118,53 \mathrm{~g}$ (jantan) dan $77,72 \mathrm{~g}$ (betina) di perairan payau, dan $126,22 \mathrm{~g}$ (jantan) dan $77,90 \mathrm{~g}$ (betina) di perairan laut selama 3 bulan. Pada polikultur udang windu 40.000 ekor dan nila merah 4.000 ekor/ha di tambak, Pirzan et al. (1992) mendapatkan berat rata-rata nila merah $108,46 \mathrm{~g}$ selama 4 bulan pemeliharaan. Untuk bandeng, Haryanti (1987) mendapatkan berat $160 \mathrm{~g}$ pada padat penebaran $6.000 \mathrm{ekor} / \mathrm{ha}$ selama $168 \mathrm{hari}$.

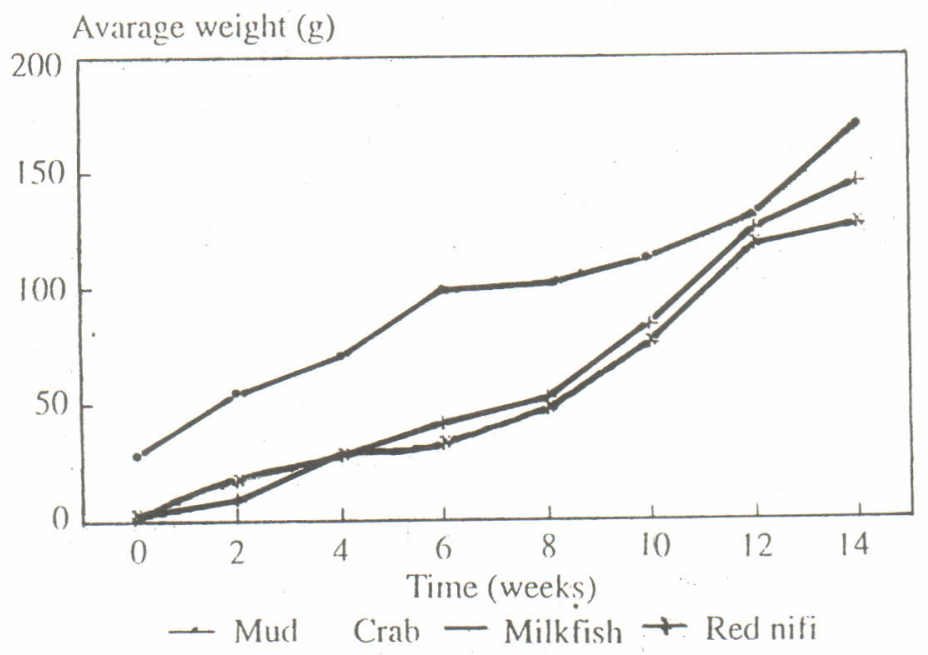

Gambar 3. Berat rata-rata kepiting bakau, bandeng dan nila merah di tambak tanah gambut selama 14 minggu

Figure 3. Average weight of mud crab, milkfish, and red nifi in brackishwater peat soil pond for 14 weeks 
Laju pertumbuhan yang diperoleh dalam percobaan ini untuk kepiting bakau, bandeng, dan nila merah berturut-turut 1,$45 ; 1,48$ dan $1,28 \mathrm{~g} / \mathrm{hari}$. Laju pertumbuhan kepiting bakau yang diperoleh dalam percobaan ini lebih besar dibandingkan dengan temuan Sulaeman et al. (1993) yaitu sebesar 1,33 g/hari di tambak yang relatif lebih baik pada padat penebaran 15.000 ekor/ha. Namun demikian hasil yang didapatkan tersebut lebih rendah dibandingkan dengan hasil penelitian Baliao (1981) dalam Samonte dan Agbayani 1991) yakni dengan laju pertumbuhan 1,61 g/hari. Dari hasil percobaan ini, secara umum memperlihatkan bahwa pertumbuhan kepiting bakau, nila merah dan ikan bandeng relatif sama dengan yang dibudidayakan pada tambak yang tergolong baik. Hal ini berarti dengan melaksanakan pengelolaan air yang baik maka tambak tanah gambut yang baru dikonstruksi telah dapat digunakan untuk budidaya berbagai komoditas budidaya perikanan seperti kepiting bakau, bandeng dan nila merah. Untuk bandeng dan nila merah masih diperlukan pengkajian khusus dalam pemanfaatan makanan alami di tambak, sebab dalam percobaan ini digunakan makanan tambahan.

\section{KESIMPULAN}

Tambak tanah gambut dapat dimanfaatkan untuk budidaya beberapa komoditas perikanan yang memiliki nilai ekonomis tinggi seperti kepiting bakau, bandeng dan nila merah. Setelah dipelihara di tambak tanah gambut selama 14 minggu, kepiting bakau, bandeng dan nila merah dapat mencapai berat berturut-turut 166,$33 ; 145,35$ dan $126,67 \mathrm{~g}$ dari berat awal berturut-turut 27,$63 ; 0,42$ dan $1,38 \mathrm{~g}$.

\section{DAFTAR PUSTAKA}

Arifin, Z. dan Z. Nasution. 1992. Hasil penelitian komponen perikanan di lahan rawa Sumatera Selatan. hal. 249-64. Dalam S.Partohardjono, dan M.Syam (eds.), Risalah Pertemuan Nasional Pengembangan Pertanian Lahan Rawa Pasang Surut dan Lebak, Cisarua, 3-4 Maret 1992. Departemen Pertanian, Jakarta.

ASEAN (Association of Southeast Asian Nations), 1976. Manual and pond culture of penaeid shrimp. ASEAN Coordinating Agency of the Philippines, Manila.

Baliao, D.D., 1983. Mud crab "Alimango" production brackishwater pond culture of prawn and crab. Research Associate, SEAFDEC, Iloilo, Philippine.

Bardach, J.E., J.H. Ryther, and W.O. McLarney, 1972. Aquaculture: The farming and husbandry of freshwater and marine organisms. John Wiley \& Sons, New York, Chichester, Brisbane, Toronto. 
Cholik, F., Rachmansyah, dan S.Tonnek, 1990. Pengaruh padat penebaran terhadap produksi nila merah, Oreochromis niloticus. J.Penel. Budidaya Pantai 6(2):87-96.

Davies, B., D.Eagle, and B.Finney, 1975. Soil management. Second edition. Farming Press Ltd., Fenton House, Wharfedale Road, Suffolk.

Gunarto, A. Mustafa, dan Suharyanto, 1987. Pemeliharaan kepiting bakau, Scylla serrata (Forskal) pada berbagai tingkat kadar garam dalam kondisi laboratorium. J.Penel. Budidaya Pantai 3(2):60-64.

Haryanti, 1987. Budidaya bandeng, Chanos chanos (Forskal) di tambak dangkal dan dalam. J.Penel. Budidaya Pantai 3(2):83-93.

Hill, B.J., 1982. The Queensland mud crab fishery. Fiheries Research Branch, Qld. Dept. of Primary Industries, Fortitude Valley, Queensland, Australia.

Klepper, O., Gt.M. Hatta, and Gt. Chairuddin, 1990. Environmental impacts of the reclamation of Potential Acid Acid Sulfat Soils in Indonesia. IARD Journal 12(2):29-34.

Le Than Hung, 1992. Integration of crustacean aquaculture with coastal rice farming in Vietnam. NAGA, The ICLARM Quarterly 15(2):27-29.

Liao, I-Chi and Su-Lin Chang, 1983. Studies on the feasibility of red tilapia culture in saline water. In International Symposium on Tilapia in Aquaculture, Nazareth, Israel 8-13 May 1983. Tel Aviv University, Tel Aviv, Israel.

Mintardjo, K., Sunaryanto, Utaminingsih, dan Hermiyaningsih, 1984. Persyaratan tanah dan air. hal. 63-89. Dalam Pedoman budidaya tambak. Balai Budidaya Air Payau, Jepara.

Mustafa, A., A.Hanafi, dan B.Pantjara, 1992. Pengaruh frekuensi pengolahan tanah terhadap kualitas tanah dan air serta pertumbuhan dan kelangsungan hidup udang windu di tambak tanah gambut bukaan baru. Laporan Penelitian. Balai Penelitian Perikanan Budidaya Pantai, Maros.

Pirzan, A.M., S.Tahe, dan A.Ismail, 1992. Polikultur udang windu, Penaeus monodon dan nila merah, Oreochromis niloticus di tambak. J.Penel. Budidaya Pantai 8(2):63-70.

Poernomo, A., 1988. Pembuatan tambak di Indonesia. Seri Pengembangan No. 7. Balai Penelitian Perikanan Budidaya Pantai, Maros.

Potter, T., 1976. The problems of fish culture associated with acid sulfat soil and methods for their improvement. Paper presented at the Twelfth Annual National Conference of the Philippine Federation of Fish Farm Producers, Iloilo, Philippines.

Prasetyo, 1988. Pembesaran ikan nila secara tunggal kelamin. Warta Litbang Pertanian 5(5)1-2. 
Samonte, G.P.B. and R.F.Agbayani, 1991. Pond culture of mud crab (Scylla serrata): An economic analysis. p. 225-31.In C.A. Angel (ed.), The mud crab, A report on the seminar convened in Surat Thani, Thailand, November 5-8 1991. Nagaraj \& Co., Madras, India.

Sulaeman, M.Tjaronge, dan A.Hanafi, 1993. Pembesaran kepiting bakau, Scylla serrata dengan konstruksi tambak yang berbeda. J.Penelitian Budidaya Pantai 9(4):41-52.

Wahyuni, E. dan W.Ismail, 1987. Beberapa kondisi lingkungan perairan kepiting bakau (Scylla serrata) di perairan Tanjung Pasir Tangerang. Jurnal Penelitian Laut 38:56-61.

Wheaton, F.W., 1977. Aquaculture engineering. John Wiley and Sons, New York. 
Lampiran 1. Kualitas air tambak tanah gambut Appendix 1. Water quality of peat soil ponds

\begin{tabular}{|c|c|c|c|c|c|c|c|c|}
\hline \multirow[t]{2}{*}{$\begin{array}{l}\text { Variabel } \\
\text { (Variable) }\end{array}$} & \multirow[t]{2}{*}{$\begin{array}{l}\text { Komoditas } \\
\text { (Commodity) }\end{array}$} & \multicolumn{7}{|c|}{$\begin{array}{l}\text { Waktu pengamatan (minggu) } \\
\text { Observation Time (week) }\end{array}$} \\
\hline & & 2 & 4 & 6 & 8 & 10 & 12 & 14 \\
\hline \multirow{3}{*}{$\begin{array}{l}\text { NO2-N } \\
\text { (ppm) }\end{array}$} & Kepiting bakau & 0,0143 & 0,0112 & 0,0064 & 0,0048 & 0,0046 & 0,0043 & 0,0036 \\
\hline & Bandeng & 0,0050 & 0,0108 & 0,0062 & 0,0057 & 0,0050 & 0,0039 & 0,0030 \\
\hline & Nila merah & 0,0074 & 0,0118 & 0,0053 & 0,0059 & 0,0049 & 0,0031 & 0,0037 \\
\hline \multirow{3}{*}{$\begin{array}{l}\text { NO3-N } \\
\text { (ppm) }\end{array}$} & Kepiting bakau & 0,0016 & 0,0043 & 0,0046 & 0,0014 & 0,0017 & 0,0013 & 0,0016 \\
\hline & Bandeng & 0,0018 & 0,0024 & 0,0039 & 0,0014 & 0,0013 & 0,0014 & 0,0010 \\
\hline & Nila merah & 0,0012 & 0,0043 & 0,0045 & 0,0014 & 0,0012 & 0,0009 & 0,0014 \\
\hline \multirow{3}{*}{$\begin{array}{l}\text { NH4-N } \\
\text { (ppm) }\end{array}$} & Kepiting bakau & 0,0635 & 0,0592 & 0,0607 & 0,0573 & 0,0541 & 0,0462 & 0,0489 \\
\hline & Bandeng & 0,0614 & 0,0590 & 0,0611 & 0,0610 & 0,0587 & 0,0521 & 0,0504 \\
\hline & Nila merah & 0,0161 & 0,0598 & 0,0660 & 0,0586 & 0,0517 & 0,0468 & 0,0468 \\
\hline \multirow{3}{*}{$\begin{array}{l}\text { PO4-P } \\
\text { (ppm) }\end{array}$} & Kepiting bakau & nd & 0,0090 & 0,0102 & 0,0094 & 0,0074 & 0,0061 & 0,0042 \\
\hline & Bandeng & nd & 0,0091 & 0,0106 & 0,0031 & 0,0045 & 0,0041 & 0,0047 \\
\hline & Nila merah & nd & 0,0059 & 0,0103 & 0,0063 & 0,0051 & 0,0039 & 0,0038 \\
\hline \multirow{3}{*}{$\begin{array}{l}\text { DOM } \\
(\mathrm{ppm})\end{array}$} & Kepiting bakau & 8,64 & 8,41 & 11,36 & 8,12 & 7,65 & 6,53 & 7,63 \\
\hline & Bandeng & 8,38 & 8,24 & 7,91 & 8,17 & 8,03 & 7,13 & 7,89 \\
\hline & Nila merah & 8,50 & 8,37 & 8,44 & 8,25 & 8,08 & 6,98 & 6,62 \\
\hline \multirow{3}{*}{$\mathrm{Fe}(\mathrm{ppm})$} & Kepiting bakau & 0,0923 & 0,1019 & 0,0923 & 0,0243 & 0,0106 & 0,0189 & nd \\
\hline & Bandeng & 0,0778 & 0,2627 & 0,0875 & nd & 0,0093 & nd & nd \\
\hline & Nila merah & 0,0802 & 0,1151 & 0,0881 & nd & 0,0069 & 0,0098 & nd \\
\hline \multirow[t]{3}{*}{$\mathrm{Al}$ (ppm) } & Kepiting bakau & nd & nd & nd & 0,66 & 0,45 & 0,39 & 0,41 \\
\hline & Bandeng & nd & nd & nd & 0,57 & 0,39 & 0,36 & 0,35 \\
\hline & Nila merah & nd & nd & nd & 0,71 & 0,62 & 0,49 & 0,44 \\
\hline \multirow{3}{*}{$\begin{array}{l}\mathrm{SO} 4 \\
\text { (ppm) }\end{array}$} & Kepiting bakau & 5,90 & 6,57 & 52,69 & 62,09 & 30,54 & 25,87 & 21,90 \\
\hline & Bandeng & 6,87 & 6,23 & 49,83 & 22,35 & 20,19 & 21,80 & 20,03 \\
\hline & Nila merah & 7,02 & 6,77 & 49,93 & 23,60 & 22,98 & 22,03 & 24,67 \\
\hline
\end{tabular}

DOM: bahan organik terlarut (dissolved organic matter) nd: $\quad$ tidak ada data (not detectable) 